\title{
KOMPETENSI KEPALA SEKOLAH DALAM PELAKSANAAN SUPERVISI PENDIDIKAN DI SDN UWEDIKAN KECAMATAN LUWUK TIMUR
}

\author{
Hasrat A. Aimang ${ }^{1)}$, Farid Haluti ${ }^{2}$ \\ ${ }^{1}$ Fakultas Keguruan Dan Ilmu Pendidikan, Universitas Muhammadiyah Luwuk \\ email: hasrat@unismuhluwuk.ac.id \\ ${ }^{2}$ Fakultas Agama Islam, Universitas Muhammadiyah Luwuk \\ email: farid@unismuhluwuk.ac.id
}

\begin{abstract}
Supervision is the development of education in the form of guidance or guidance toward improving the situation of education in general and improving the quality of teaching and learning and learning in particular. Supervision also assist in the development of teaching and learning situation in order to obtain better conditions.The purpose of this study was to analyze Competence Implementation Supervision Principal in Education in Elementary School District of Luwuk Uwedikan East. While the usefulness of research that provide scientific information to the perpetrators of both the level of school education and the government about the competence of principals of this research will be conducted in February until May 2015 with the location of the District research SDN Uwedikan East Luwuk, Methods This study used a descriptive explanatory. Technique data collecting conducted quantitative and qualitative, with data collection for the pilot and two data collection instruments in order to research the truth. To obtain data regarding the competency of school principals in the implementation of the supervision of education that will be collected, processed and analyzed, the researchers used several methods of collecting data through observation, interviews, questionnaires and Documentation, instrument used in these documentation techniques are guidelines on matters needed to strengthen the information obtained through observation, interviews and questionnaires carried out. From the research while through the distribution of a questionnaire to show the competence of principals in the implementation of educational supervision in SDN Uwedikan District of East Luwuk based on the assessment scale is high with the acquisition of the average score was 71.3 .
\end{abstract}

Keywords: competence, education supervision

\section{PENDAHULUAN}

Sejalan dengan tantangan pendidikan yang semakin maju demi memenuhi mutu pendidikan yang di inginkan dikarenakan pendidikan merupakan hal yang terpenting dalam menentukan mutu sumberdaya manusia. Keungulan bangsa tidak dilihat dari segi melimpahnya sumberdaya alamnya. Mutu sumberdaya manusia sangat berhubungan dengan mutu pendidikan yang dihasilkan, mutu pendidikan juga di tentukan oleh kondisi yang baik dan memenuhi syarat dari segala komponen pendidikan.

Mutu pendidikan akan tercapai apabila proses, keluaran, kepala sekolah, guru, sarana prasarana serta biaya tersedia dapat mendukungan proses pendidikan yang dijalankan. Sebagai sebuah organisasi, sekolah merupakan lembaga yang bersifat kompleks dan unik. Di dalamnya terdapat berbagai dimensi yang saling berkait dan menentukan, serta memiliki ciri tertentu yang tidak dimiliki organisasi lain. Berkembang tidaknya sekolah dipengaruhi oleh kepemimpinan dari kepala sekolah yang merupakan pejabat formal, manajer, pemimpin, pendidik, dan juga sebagai staf.

Kepala sekolah sebagai supervisor harus diwujudkan dalam kemampuan menyusun, dan melaksanakan program supervisi pendidikan, serta memanfaatkan hasilnya. Kemampuan menyusun program supervisi pendidikan harus diwujudkan dalam penyusunan program supervisi kelas, pengembangan program supervisi untuk kegiatan ekstra kurikulum, pengembangan program supervisi perpustakaan, 
laboratorium, dan ujian. Kemampuan melaksanakan program supervisi pendidikan harus diwujudkan dalam pelaksanakan program supervisi klinis, program supervisi nonklinis, dan program supervisi kegiatan ekstra kurikuler. Sedangkan kemampuan memanfaatkan hasil supervisi harus diwujudkan dalam pemanfaatan hasil supervisi untuk meningkatkan kinerja tenaga kependidikan dan pemanfaatan hasil supervisi untul mengembangkan sekolah.

\section{KAJIAN LITERATUR}

\subsection{Konsep Dasar Supervisi Pendidikan}

Supervisi menurut Hadari Nawawi (1997:99) adalah "Kegiatan pengawasan yang dilakukan oleh pejabat terhadap bawahanya untuk melakukan tugas-tugas dan kewajibannya dengan baik sesuai pertelaan tugas digariskan"

M. Rifai (1982:20) mengemukakan bahwa supervisi merupakan pengawasan yang lebih profesional dibandingkan dengan pengawasan umum karena perkembangan kemajuan pendidikan yang membutuhkannya, yaitu pegawasan akademik yang mendasarkan kepada kemampuan ilmiah. Pendekatannya bukan lagi pengawasan manajemen biasa yang bersifat in human, melainkan menuntut kemampuan profesional yang demokratis dan humanistik oleh para pengawas dalam melaksanakannya : karena kemajuan ilmu pengetahuan dan teknologi, diperlukan pengawasan yang lebih profesional, yang menuntut kemampuan profesional dari para pengawasnya, dan bukan hanya wewenang administrasi saja.

Menurut Purwanto (1987) Supervisi ialah suatu aktivitas pembinaan yang direncanakan untuk membantu para guru dan pegawai sekolah lainnya dalam melakukan pekerjaan mereka secara efektif.

Supervisi adalah bagian dari perangkat pelaksana pendidikan yang bertujuan untuk melaksanakan proses pengawasan yang selanjutnya dilakukan pembinaan yang dilakukan secara rutin.

\subsection{Tujuan Supervisi Pendidikan}

Tujuan supervisi adalah untuk mengembangkan situasi proses pembelajaran yang lebih baik melalui pembinaan dan peningkatan profesi mengajar. Secara lebih terperinci tujuan superevisi adalah (Burhanuddin, 2005 : 100) : a. Meningkatkan efektivitas dan efisiensi proses pembelajaran.

b. Mengendalikan penyelenggaraan bidang tehnis edukatif di sekolah sesuai dengan ketentuan dan kebijakan yang telah ditetapkan.

c. Menjamin agar kegiatan sekolah berlangsung sesuai dengan ketentuan yang berlaku, sehingga berjalan lancar dan memperoleh hasil yang optimal.

d. Menilai sekolah dalam pelaksanaan tugasnya,

Memberikan bimbingan langsung untuk memperbaiki kesalahan, kekuranga, membantu memecahkan masalah yang dihadapi sekolah.

\subsection{Program Supervisi Pendidikan}

Program supervisi yang baik berisi kegiatan untuk meningkatkan kemampuan profesional guru dalam hal. (Djam'an Satori,1997:31) :

1. Kemampuan menjabarkan kurikulum kedalam program catur wulan.

2. Kemampuan menyusun perecanaan mengajar atau satuan pelajaran.

3. Kemampuan melaksanakan kegiatan belajar mengajar dengan baik.

4. Kemampuan menilai proses dan hasil belajar

5. Kemampuan untuk memberikan umpan balik secara teratur dan terus menerus.

6. Kemampuan membuat dan menggunakan alat bantu mengajar secara sederhana.

7. Kemampuan menggunakan/memanfaatkan lingkungan sebagai sumber dan media pengajaran.

8. Kemampuan membimbing dan melayani murid yang mengalami kesulitan dalam belajar.

9. Kemampuan mengatur waktu dan menggunakannya secara efisien untuk menyelesaikan program-program belajar murid.

10. Kemampuan memberikan pelajaran dengan memperhatikan perbedaan individual diantara para siswa.

Kemampuan mengelola kegiatan belajar mengajar ko dan ektra kurikuler serta kegiatan-kegiatan lainnya yang berkaitan pembelajaran siswa.

2.4. Kepala Sekolah Sebagai Supervisor Supervisi sesungguhnya dapat dilaksanakan oleh kepala sekolah yang 
berperan sebagai supervisor, tetapi dalam sistem organisasi pendidikan modern diperlukan supervisor khusus yang lebih independent, dan dapat meningkatkan objektivitas dalam pembinaan dan pelaksanaan tugasnya.

Jika supervisi dilaksanakan oleh kepala sekolah, maka ia harus mampu melakukan berbagai pengawasan dan pengendalian untuk meningkatkan kinerja tenaga kependidikan. Pengawasan dan pengendalian ini merupakan kontrol agar kegiatan pendidikan di sekolah terarah pada tujuan yang telah ditetapkan. Pengawasan dan pengendalian juga merupakan tindakan preventif untuk mencegah agar para tenaga kependidikan tidak melakukan penyimpangan dan lebih berhati-hati dalam melaksanakan pekerjaannya.

Pengawasan dan pengendalian yang dilakukan kepala sekolah terhadap tenaga kependidikannya khususnya guru, disebut supervisi klinis, yang bertujuan untuk meningkatkan kemampuan profesional guru dan meningkatkan kualitas pembelajaran melalui pembelajaran yang efektif.

\section{METODE PENELITIAN}

Penelitian ini akan dilaksanakan pada bulan Februari sampai dengan Oktober 2015 dengan lokasi penelitian untuk pengambilan sampel dalam penelitian ini adalah di SDN Uwedikan Kecamatan Luwuk Timur

Metode Penelitian ini menggunakan deskriptif eksplanatori. Teknik pengumpulan datanya dilakukan secara kuntitatif dan kualitatif. Dengan pengumpulan data untuk uji coba instrumen dan dua pengumpulan data dalam rangka penelitian yang sebenarnya. Untuk memperoleh data mengenai kopetensi kepala sekolah dalam pelaksanaan supervisi pendidikan yang akan dikumpulkan, diolah dan dianalisis, maka peneliti menggunakan beberapa metode pengumpulan data melalui Observasi, Wawancara, Kuesioner dan Dokumentasi, Instrumen yang digunakan dalam teknik dokumentasi ini adalah pedoman tentang hal-hal yang dibutuhkan untuk memperkuat informasi yang diperoleh melalui observasi, wawancara dan kuesioner yang dilakukan.

Dalam penelitian ini menggunakan teknik analisis kuantitatif yang diperoleh melalui pernyataan responden yang terdapat pada data kuesioner, dan selanjutnya untuk pengecekan keakuratan data tersebut dilakukan pula wawancara, observasi serta dokumentasi. Sedangkan dalam mendeskripsikan data yang diperoleh secara kuantitatif digunakan statistik deskriptif, hal ini dilakukan dalam penelitian ini untuk memperoleh hasil informasi yang benar. Selanjutnya dalam pengolahan data terdapat dua langkah yang digunakan, sebagai berikut :

\section{Seleksi dan Klasifikasi Data}

Langkah pertama yang dilakukan oleh peneliti sebelum melakukan pengolahan data adalah berupa pengecekan atau pengoreksian data angket yang telah terkumpul, tujuannya untuk menghilangkan kesalahan-kesalahan yang terdapat pada pencatatan dilapangan dan bersifat koreksi. Sedangkan Langkah-langkah yang dilakukan adalah sebagai berikut: a) memeriksa apakah semua responden dapat mengisi angket yang dibagikan; b) memeriksa semua pertanyaan dalam angket untuk memastikan jawaban sesuai dengan petunjuk yang diberikan; 3) memeriksa apakah data yang terkumpul tersebut layak untuk diolah.

Selanjutnya setelah melakukan seleksi data adalah mengklasifikasikan data berdasarkan indicator yang diteliti, kemudian memberikan bobot skor untuk setiap alternative jawaban dalam pemberian skor digunakan skala Likert yang merupakan salah satu cara untuk menentukan skor.

Tabel 1

Skor dan Alternatif Jawaban Angket

\begin{tabular}{|c|c|c|}
\hline Skor & $\begin{array}{c}\text { Alternatif } \\
\text { Jawaban }\end{array}$ & Realisasi \\
\hline 5 & Selalu & $100 \%$ \\
\hline 4 & Sering & $75 \%$ \\
\hline 3 & $\begin{array}{c}\text { Kadang- } \\
\text { Kadang }\end{array}$ & $50 \%$ \\
\hline 2 & Jarang & $25 \%$ \\
\hline 1 & Tidak Pernah & $0 \%$ \\
\hline
\end{tabular}

Perhitungan terhadap data yang sudah diberikan skor berdasarkan jenis data yang dikumpulkan yaitu data kualitatif yang kemudian diubah menjadi kuantitatif, maka teknik yang digunakan adalah analisis statistik, yaitu dengan menggunakan rumus statistik (prosentase) yang digunakan untuk mendeskripsikan hasil penelitian dengan rumus sebagai berikut:

$$
\mathrm{P}=\mathrm{f} \quad \mathrm{x} 100 \%
$$




$$
\begin{aligned}
& \mathrm{P}=\mathrm{N} \\
& \mathrm{f}=\text { Prosentase Jawaban } \\
& \mathrm{N}=\quad \text { Number Of Cases (banyaknya } \\
& \text { responden) }
\end{aligned}
$$

2. Pengolahan data melalui perhitungan dengan Weighted Means Score (WMS).

Dalam pengolahan data adalah hal yang terpenting dalam penelitian. Setelah penelitian dilaksanakan perlu dilakukan penyimpulan hasil penelitian agar dapat disimpulkan secara mendalam, hal ini dilakukan agar dapat menjawab permasalahan yang diteliti. Pengolahan data dimaksudkan agar data yang diteliti dapat berarti, sehingga dalam pengolahan data haruslah dilakukan secara sistematis agar peneliti dapat menggunakan data yang diolah untuk dapat disimpulkan.

Pada penelitian ini rumus yang digunakan adalah Weighted Means Score (WMS). Teknik ini digunakan untuk mendapatkan kecenderungan skor yang diberikan oleh responden pada setiap item pertanyaan sesuai dengan kriteria atau tolak ukur yang digunakan.

Menurut Sudjana (2005:67) teknik Weighted Means Score (WMS) adalah untuk menghitung kecenderungan jawaban responden terhadap variable penelitian. Adapun langkah-langkah yang dilakukan dalam pengolahan data pada penelitian ini adalah sebagai berikut :

a. Pemberian bobot nilai terhadap masingmasing alternative jawaban diberikan oleh responden, sesuai dengan pertanyaan yang diberikan. Angket yang digunakan adalah Skala Likert dengan rentang pilihan 1 sampai dengan 5

b. Menghitung frekuensi dari alternative jawaban responden pada setiap item pertanyaan.

c. Mencari jumlah nilai jawaban yang menjadi pilihan responden di setiap pertanyaan, dengan menghitung frekuensi responden yang memilih alternative jawaban yang diberikan tersebut selanjutnya dikalikan dengan bobot nilai alternative itu sendiri.

d. Menghitung nilai rata-rata untuk pada setiap item pertanyaan pada angket, dengan menggunakan rumus Weighted Means Score (WMS) sebagaimana yang dikemukakan oleh Sudjana (2005:67) adalah sebagai berikut :

$$
\bar{X}=\frac{X i}{N}
$$

Keterangan :

$$
\begin{aligned}
& \bar{X}=\text { Skor rata-rata yang dicari } \\
& X i=\begin{array}{l}
\text { Jumlah skor gabungan (hasil } \\
\text { perkalian frekuensi dengan }
\end{array} \\
& \quad \begin{array}{l}
\text { bobot nilai untuk setiap } \\
\text { alternative jawaban). }
\end{array} \\
& N=\text { Jumlah responden }
\end{aligned}
$$

e. Menentukan variabel yang diukur berdasarkan indicator yang diteliti, maka digunakan skala penilaian oleh Riduwan (2010:15), yaitu sebagai berikut:

Tabel 2

Kriteria Penilaian

\begin{tabular}{|c|c|}
\hline Rentang Nilai & Kriteria \\
\hline $86-100 \%$ & Sangat Tinggi \\
\hline $71-85 \%$ & Tinggi \\
\hline $51-70 \%$ & Cukup \\
\hline $35-50 \%$ & Rendah \\
\hline $0-34 \%$ & Sangat Rendah \\
\hline
\end{tabular}

Dari hasil analisis kuantitatif selanjutnya dalam memperdalam dalam keakuratan hasil tersebut, maka dilakukan wawancara, observasi dan dokumentasi dilokasi penelitian.

\section{HASIL DAN PEMBAHASAN}

Analisis Tahapan Pra Supervisi Pendidikan Terhadap Kompetensi Kepala Sekolah.

Pengawasan atau supervisi merupakan bagian tidak terpisahkan dalam upaya peningkatan prestasi belajar dan mutu sekolah, sehingga kesiapan kepala sekolah dalam melaksanakan pengawasan sangat menentukan mutu sekolah.

Hasil analisis data terhadap skor tahapan pra supervisi pendidikan terhadap kompetensi kepala sekolah di SDN Uwedikan yang dijabarkan dalam 8 item pernyataan sehingga dari pernyataan nomor 1 sampai nomor 8 dilakukan dengan perhitungan teknik Weighted Means Scored (WMS) adalah sebagai berikut. 
Tabel 3

Hasil Perhitungan Persentase Skor Jawaban Responden dalam

Tahapan pra supervisi pendidikan terhadap kompetensi kepala sekolah

di SDN Uwedikan

\begin{tabular}{|c|c|c|c|c|c|c|c|c|c|c|c|c|c|c|}
\hline \multirow{3}{*}{ Indikator } & \multirow{3}{*}{$\begin{array}{c}\text { No } \\
\text { Item }\end{array}$} & \multicolumn{10}{|c|}{ Bobot Skor } & \multicolumn{2}{|c|}{ Jumlah } & \multirow{3}{*}{$\begin{array}{c}\% \\
\text { skor }\end{array}$} \\
\hline & & \multicolumn{2}{|c|}{5} & \multicolumn{2}{|c|}{4} & \multicolumn{2}{|c|}{3} & \multicolumn{2}{|c|}{2} & \multicolumn{2}{|c|}{1} & & & \\
\hline & & $\mathbf{F}$ & $\mathbf{X}$ & $\mathbf{F}$ & $\mathbf{X}$ & $\mathbf{F}$ & $\mathbf{X}$ & $\mathbf{F}$ & $\mathbf{X}$ & $\mathbf{F}$ & $\mathbf{X}$ & $\mathbf{F}$ & $\mathbf{X}$ & \\
\hline \multirow{9}{*}{$\begin{array}{l}\text { Pra supervisi } \\
\text { pendidikan } \\
\text { terhadap } \\
\text { kompetensi kepala } \\
\text { sekolah }\end{array}$} & 1 & 0 & 0 & 7 & 28 & 1 & 3 & 0 & 0 & 0 & 0 & 8 & 31 & 77,5 \\
\hline & 2 & 0 & 0 & 5 & 20 & 2 & 6 & 1 & 2 & 0 & 0 & 8 & 28 & 70 \\
\hline & 3 & 0 & 0 & 6 & 24 & 2 & 6 & 0 & 0 & 0 & 0 & 8 & 30 & 75 \\
\hline & 4 & 0 & 0 & 0 & 0 & 1 & 3 & 7 & 14 & 0 & 0 & 8 & 17 & 42,5 \\
\hline & 5 & 2 & 10 & 6 & 24 & 0 & 0 & 0 & 0 & 0 & 0 & 8 & 34 & 85 \\
\hline & 6 & 1 & 5 & 1 & 4 & 6 & 18 & 0 & 0 & 0 & 0 & 8 & 27 & 67,5 \\
\hline & 7 & 7 & 35 & 1 & 4 & 0 & 0 & 0 & 0 & 0 & 0 & 8 & 39 & 97,5 \\
\hline & 8 & 1 & 5 & 4 & 16 & 2 & 6 & 1 & 2 & 0 & 0 & 8 & 29 & 72,5 \\
\hline & \multicolumn{14}{|c|}{ Rata-Rata $=587,5 / 8=73.44$} \\
\hline
\end{tabular}

Keterangan :

$\mathrm{F}=$ Frekuensi responden yang menjawab sesuai dengan kategori jawaban

$\mathrm{X}=$ Frekuensi dikalikan dengan bobot nilai kategori jawaban

Sehingga berdasarkan tabel yang disajikan di atas dapat disimpulkan nilai rata-rata persentase skor peroleh pada tahapan pra supervisi pendidikan terhadap kompetensi kepala sekolah di SDN Uwedikan, maka diperoleh skor rata-rata 73,44, jika dikonsutasikan pada kriteria penilaian maka disimpulkan kriteria yang diperoleh adalah Tinggi

\section{Analisis Tahapan Pelaksanaan Supervisi Pendidikan Oleh Kepala Sekolah.}

Kegiatan kepala sekolah sebagai pengawas dalam sekolah adalah menilai dan membina

Tabel 4

Hasil Perhitungan Persentase Skor Jawaban Responden dalam

Tahapan pelaksanaan supervisi pendidikan oleh kepala sekolah di SDN Uwedikan

\begin{tabular}{|c|c|c|c|c|c|c|c|c|c|c|c|c|c|c|}
\hline & $\begin{array}{l}\text { asil P } \\
\text { ahapa }\end{array}$ & & & & $\begin{array}{l}\mathrm{T} \\
\mathrm{se} \\
\mathrm{rvi}\end{array}$ & $i n$ & $\begin{array}{l}\text { Jaw } \\
\text { did }\end{array}$ & $\begin{array}{l}\text { bar } \\
\text { an }\end{array}$ & Res & $\begin{array}{l}\text { ond } \\
\text { epa }\end{array}$ & $\begin{array}{l}\mathrm{nd} \\
\mathrm{se}\end{array}$ & & & \\
\hline \multirow{3}{*}{ Indikator } & \multirow{3}{*}{$\begin{array}{c}\text { No } \\
\text { Item }\end{array}$} & \multicolumn{10}{|c|}{ Bobot Skor } & \multicolumn{2}{|c|}{ Jumlah } & \multirow{3}{*}{$\begin{array}{c}\% \\
\text { skor }\end{array}$} \\
\hline & & \multicolumn{2}{|c|}{5} & \multicolumn{2}{|c|}{4} & \multicolumn{2}{|c|}{3} & \multicolumn{2}{|c|}{2} & \multicolumn{2}{|c|}{1} & \multirow{2}{*}{$\mathbf{F}$} & \multirow{2}{*}{$\mathbf{X}$} & \\
\hline & & $\mathbf{F}$ & $\mathbf{X}$ & $\mathbf{F}$ & $\mathbf{X}$ & $\mathbf{F}$ & $\mathbf{X}$ & $\mathbf{F}$ & $\mathbf{X}$ & $\mathbf{F}$ & $\mathbf{X}$ & & & \\
\hline \multirow{4}{*}{$\begin{array}{l}\text { Pelaksanaan } \\
\text { supervisi } \\
\text { pendidikan oleh } \\
\text { kepala sekolah }\end{array}$} & 1 & 1 & 5 & 7 & 28 & 0 & 0 & 0 & 0 & 0 & 0 & 8 & 33 & 82,5 \\
\hline & 2 & 0 & 0 & 4 & 16 & 2 & 6 & 2 & 4 & 0 & 0 & 8 & 26 & 65 \\
\hline & 3 & 0 & 0 & 0 & 0 & 6 & 18 & 1 & 2 & 1 & 1 & 8 & 21 & 52,5 \\
\hline & 4 & 0 & 0 & 0 & 0 & 4 & 12 & 3 & 6 & 1 & 1 & 8 & 19 & 47,5 \\
\hline
\end{tabular}

penyelenggaraan pendidikan pada satuan pendidikan/sekolah baik pada sekolah negeri maupun swasta yang menjadi tanggung jawabnya. Penilaian itu dilakukan untuk penentuan derajat kualitas berdasarkan kriteria (tolak ukur) yang ditetapkan terhadap penyelenggaraan pendidikan di sekolah

Hasil analisis data terhadap skor tahapan pelaksanaan supervisi pendidikan oleh kepala sekolah di SDN Uwedikan yang dijabarkan dalam 9 item pernyataan sehingga dari pernyataan nomor 9 sampai nomor 17 dilakukan dengan perhitungan teknik Weighted Means Scored (WMS) adalah sebagai berikut. 


\begin{tabular}{|c|c|c|c|c|c|c|c|c|c|c|c|c|c|c|}
\hline \multirow{3}{*}{ Indikator } & \multirow{3}{*}{$\begin{array}{c}\text { No } \\
\text { Item }\end{array}$} & \multicolumn{10}{|c|}{ Bobot Skor } & \multicolumn{2}{|c|}{ Jumlah } & \multirow{3}{*}{$\begin{array}{c}\% \\
\text { skor }\end{array}$} \\
\hline & & \multicolumn{2}{|c|}{5} & \multicolumn{2}{|c|}{4} & \multicolumn{2}{|c|}{3} & \multicolumn{2}{|c|}{2} & \multicolumn{2}{|c|}{1} & \multirow{2}{*}{$\mathbf{F}$} & \multirow{2}{*}{$\mathbf{X}$} & \\
\hline & & $\mathbf{F}$ & $\mathbf{X}$ & $\mathbf{F}$ & $\mathbf{X}$ & $\mathbf{F}$ & $\mathbf{X}$ & $\mathbf{F}$ & $\mathbf{X}$ & $\mathbf{F}$ & $\mathbf{X}$ & & & \\
\hline & 5 & 2 & 10 & 5 & 20 & 1 & 3 & 0 & 0 & 0 & 0 & 8 & 33 & 82,5 \\
\hline & 6 & 0 & 0 & 2 & 8 & 6 & 18 & 0 & 0 & 0 & 0 & 8 & 26 & 65 \\
\hline & 7 & 0 & 0 & 1 & 4 & 5 & 15 & 2 & 4 & 0 & 0 & 8 & 23 & 57,5 \\
\hline & 8 & 2 & 10 & 5 & 20 & 1 & 3 & 0 & 0 & 0 & 0 & 8 & 33 & 82,5 \\
\hline & 9 & 3 & 15 & 5 & 20 & 0 & 0 & 0 & 0 & 0 & 0 & 8 & 35 & 87,5 \\
\hline
\end{tabular}

Keterangan:

$\mathrm{F}=$ Frekuensi responden yang menjawab sesuai dengan kategori jawaban

$\mathrm{X}=$ Frekuensi dikalikan dengan bobot nilai kategori jawaban

Sehingga berdasarkan tabel yang berkaitan pula dengan pemanfaatan dan disajikan di atas dapat disimpulkan nilai ratarata persentase skor peroleh pada tahapan pelaksanaan supervisi pendidikan oleh kepala sekolah di SDN Uwedikan, maka diperoleh skor rata-rata 69,17 , jika dikonsutasikan pada kriteria penilaian maka disimpulkan kriteria yang diperoleh adalah cukup

Keterampilan atau skill dapat dikonotasikan sebagai sekumpulan pengetahuan dan keterampilan yang harus dikuasai. Keterampilan supervisor adalah sekumpulan pengetahuan/kemampuan yang harus dikuasai dalam melaksanakan pembinaan guru.

Depdibud (1986) Teknik-teknik supervise meliputi : kunjungan kelas, pertemuan pribadi, rapat dewan guru/staf, kunjungan antar kelas kunjungan sekolah, kunjungan antar sekolah, pertemuan dalam kelompok kerja, penerbitan bulletin professional dan penataran. Dalam teknik-teknik supervise mengisyaratkan agar kepala sekolah dalam melaksanakan fungsinya sebagai supervisor harus melakukan teknik-teknik diatas agar dalam menghasilkan mutu pendidikan yang baik.

Sasaran akhir supervise pendidikan yaitu terciptanya suasana pembelajaran yang memungkinkan peserta didik dapat mengembangkan potensinya secara optimal. Untuk mewujudkan hal tersebut, diperlukan pembinaan secara intensif bagi guru-guru yang berkaitan dengan keterampilan mengajar. Sebagai suatu potensi, mengajar merupakan sesuatu yang kompleks, karena sasaran kegiatannya adalah manusia yang memiliki berbagai keunikan. Selain itu, pengembangan iptek, seni dan budaya.

Probematika yang dihadapi guru dan cara-cara pemecahannya perlu adanya pengetahuan dari supervisor untuk memahami penyebabnya. Supervisor dituntut kemampuannya menganalisis kelemahan berdasarkan data yang obyektif dengan mengadakan pendekatan formal dan informal dan menghindari pola yang bersifat tradisonal. Dengan penelitian yang dilakukan kelemahan yang dimiliki oleh supervisor mempengaruhi system pembelajaran yang dilakukan di sekolah tersebut.

\section{KESIMPULAN}

Berdasarkan hasil sebaran angket dari penelitian kompetensi kepala sekolah dalam pelaksanaan supervisi pendidikan di SDN Uwedikan Kecamatan Luwuk Timur Kabupaten Banggai dilihat dari capai persentase dengan memiliki kompetensi yang tinggi dilihat dari 2 (dua) aspek kompetensi, dengan kesimpulan sebagai berikut :

1. Kompetensi dalam pra supervisi menunjukan pada kriteria tinggi.

2. Kompetensi dalam pelaksanaan supervisi menunjukan pada kriteria cukup.

\section{REFERENSI}

Arikunto Suharsimi. Dasar-Dasar Supervisi. Buku Pegangan Kuliah, Jakarta. Reneka Cipta, 2004

http://eprints.walisongo.ac.id/344/4/Asyhari Tesis Bab2.pdf 
Masaong, Supervisi Pendidikan, Untuk Pendidikan Yang Lebih Baik, Gorontalo:Sentra Media, 2011

Purwanto, M.Ngalim, Administrasi dan Supervisi Pendidikan, Bandung:Remaja Rosdakarya, 2005

Masaong, Ansar, Manajemen Berbasis Sekolah. Malang : Sentral Media, 2011
Rivai Moh. Administrasi Dan Supervisi Pendidikan. Jilid 1. Bagian Administrasi. Bandung. Yenmars, 1982

Sutisna Oteng, Administrasi Pendidikan, Dasar Teoritis Untuk Praktek Profesional. Bandung. Angkasa, 1983

Suhardan, H. Dadang, Supervisi Profesional, Bandung:Alfabeta, 2010 